\title{
TCOM \\ Chanting to the choir: the dialogical failure of antithetical climate change blogs
}

\section{Jennifer Metcalfe}

Abstract

Keywords

DOI

Introduction
Blogs provide potential for publics to engage more deliberatively through dialogue in controversial science than one-way dissemination methods. This study investigated who was commenting on two antithetical climate change blogsites; how they were commenting; and the quality of their dialogue. Most research into science blogs has focused on bloggers rather than commenters. This study found that both blogsites were dominated by a small number of commenters who used contractive dialogue to promote their own views to like-minded commenters. Such blogsites are consolidating their own polarised publics rather than deliberately engaging them in climate change science.

Environmental communication; Public engagement with science and technology

https://doi.org/10.22323/2.19020204

Submitted: 4th February 2020

Accepted: 3rd April 2020

Published: 14th April 2020

A commonly-held assumption is that people make 'better' decisions once they are informed and understand scientific-based knowledge, however, it is becoming clear that credible facts and established knowledge are not driving public policies about urgent issues such as climate change [Grant, 2016; Nisbet and Scheufele, 2004; Roberts, 2013]. The traditional means of diffusing knowledge from scientists to various publics, generally through mass media, publications, lectures and exhibitions, has long been questioned by those researching science communication. Those describing theoretical models of science communication have called for more interactive and deliberative communication where scientists more actively engage with publics [Horst and Michael, 2011; Jackson, Barbagallo and Haste, 2005; Kurath and Gisler, 2009; Nisbet and Scheufele, 2004].

It is against this background that the dialogic tools of social media appear to hold promise for more deliberatively engaging latent publics [i.e. those who are disinterested but can be persuaded to become more engaged with science; Mohr, Raman and Gibbs, 2013]. Indeed, much has been made of the potential use of social 
media, including blogs, for giving publics a greater voice in contested science issues compared to traditional media [Colson, 2011; Wilcox, 2012].

This study builds on existing research about science bloggers and the content of their blogs [e.g. Riesch and Mendel, 2013, who researched the distinctive norms of the U.K. 'badscience' blog communities] or the discourse of their blogs [e.g. Luzón, 2013, who analysed science bloggers strategies to communicate and recontextualise scientific discourse]. Scholars have identified a variety of motivations for people to engage in science blogging. For example, Trench [2012] found various motivations for science bloggers, including to enable conversations with the public; to find collaborators; to increase understanding of the science; and to gain feedback. Schäfer [2012] found that science bloggers' motivations ranged from giving them "an opportunity to discuss their findings with laypeople" to engaging people in "discussions of scientific issues that do not typically take place in the scientific literature" to enabling "the public to be included more extensively in science" [2012, p. 350].

Despite the growing body of research into the activities of science bloggers and blogs, there has been remarkably little research looking at how commenters (those who respond to blogposts and those who respond to the comments of others) engage with science-based blogs. Jarreau and Porter [2018] looked at the profiles and motivations of science blog users, but not how they engaged with blogs. Huber, Wetzstein and Aichberger [2019] applied discourse analysis to user comments in two Austrian newspapers to examine discourse about a publicly funded social science study of Islamic kindergartens.

With specific regard to the use of blogs in climate change communication, most recently, Lörcher and Taddicken [2017] explored the diversity of topics and perceptions of climate change discourse by quantitatively analysing reader comments to German journalistic articles and scientific expert blogs. Collins and Nerlich [2015] investigated online comments to climate change articles in the Guardian. Graham [2013] also analysed the comments made to articles published in the Guardian about the 2009 United Nations Climate Change Summit in Copenhagen. He stressed the importance of such analysis [2013, p. 117]: "It is only through examining the functioning and nature of comment fields that we begin to understand the potential they offer to online journalism and the public sphere". Likewise, it is only through examining how publics engage with social media about science that we can understand what such tools mean for theorised and practical science communication.

Using qualitative methods, I investigated the comments on two antithetical blogs on climate change science: https:/ / skepticalscience.com/ and http://joannenova.com.au/. These blogs were chosen because they were well-established, had global reach, were written by science communicators, and aimed to use scientific information as their base. I chose antithetical blogs to examine whether commenters opposed to the consensus science of climate change engaged differently to those supportive of it. My reasoning was that such an investigation might reveal how commenters with such polarised views might be engaged more deliberatively with the science. However, my investigation of two climate change blogs among thousands does not intend to be generalisable or representative of all climate change blogs. As Schäfer [2012, p. 529] notes the 
climate science debate makes for a rich 'blogosphere' (defined as all the blogs on a specific topic, and their interconnections) where climate science proponents and deniers are seen to be "very present online". It is virtually impossible to count the total number of blogs addressing climate change [Elgesem, Steskal and Diakopoulos, 2014]. Rather than being representative of the climate change blogosphere, the study presented in this paper provides an in-depth examination of the engagement occurring among publics on both sides of a highly controversial issue: climate change. The findings are contingent on that context and contribute to an emerging area of study: how publics engage with climate change science online

\section{The dialogic potential of blogs}

When blogs, along with other social media tools, first arose in the mid-1990s they appeared to afford more opportunities to expand the dialogic space for the democratic deliberation of science with various publics. A review of the literature identified five major perceived dialogical benefits of blogs for engaging publics with science:

(1) Transform news from being a one-way dissemination of information and opinion to a dialogue where different views are heard and (ideally) valued [Cahill and Ward, 2007; Graham, 2013; Jenkins, 2006; Meraz, 2011; Schäfer, 2012; Wilcox, 2012];

(2) Amplify the voice of publics by allowing them to participate in scientific debates alongside traditional media, government and science [Cahill and Ward, 2007; Carvalho, 2010; Trench, 2012];

(3) Bypass the framings of scientific reporting by the mainstream media, allowing publics to access and engage with a broader range of perspectives on scientific controversies [Colson, 2011; Graham, 2013; Schmidt, 2008];

(4) Offer the opportunity for publics interested in science to explore the complexities of science and to use sources of information and news outside of traditional mass media [Lemonick, 2010; Luzón, 2013; Readfearn, 2010; Schmidt, 2008; Ritson, 2016; Trench, 2012]; and

(5) Enable scientists, journalists and science communicators to engage with publics to explain the scientific contexts behind the news [Bell, 2012; Colson, 2011; Jarreau and Porter, 2018; Luzón, 2013; Swain, 2012; Wilkins, 2008].

Some scholars see the ability of science blogs to more directly engage publics as being an expression of the move over the past three decades towards more participatory science communication [Colson, 2011; Kahle, Sharon and Baram-Tsabari, 2016; Pearce, Brown et al., 2015]. Scholars theorise that a new two-way style of science communication replaced the deficit model of one-way communication in response to increasing signs of public unease with science during the 1980s [Irwin and Wynne, 1996; Trench, 2008]. Jackson, Barbagallo and Haste [2005, p. 350] describe the two-way dialogue model as more deliberative in the face of public controversies in that it gives: "a context in which society (including scientists) can address the issues that are arising from new 
developments in science... it locates scientific developments in a wider social context and enables the inclusion of a wider range of expertise with regard to the implications of such developments". The dialogue model of communication recognises and values the role of various publics along with scientists and policy makers in reflecting upon, sharing knowledge about, creating new knowledge, and making decisions about science that affects society [Bubela et al., 2009; Joly and Kaufmann, 2008; Miller, Fahy and the ESConet Team, 2009]. With this style of science communication, more critical discussion between publics can occur about the science. Science blogs where there are opportunities for two-way engagement in the science appear to provide a tool where such discussions can occur.

However, some studies indicate that the full dialogic potential of social media is yet to be fully realised by scientist and scientific institutions [e.g. Lee, VanDyke and Cummins, 2018; Yuan et al., 2017]. Other scholars [e.g. Kahan et al., 2012; Pearce, Brown et al., 2015; Peters et al., 2014; Ritson, 2016; Trench, 2012] are cautious about the real dialogical potential of science blogs. Kouper [2010, p. 1] highlights the potential of science blogs as spaces for public discourse but concludes that they can also be "used to reinforce the traditional top-down model of science communication". However, these studies examined communication through social media between experts to publics; they did not examine the conversations between publics such as happens with blogs. The research reported in this paper looks specifically at the commenters to two blogs and how they dialogically interact with each other.

The main question this empirical study addresses is: are publics engaging dialogically with each other in blogs about climate change? Three subsidiary research questions explore this issue in depth with the two climate change blogs:

(1) What publics are engaging in the blogs, and what appears to be motivating them to engage?

(2) How are commenters engaging with each other through their conversations, and what does this tell us about the dialogical nature of the discussion?

(3) What is the quality of dialogue between the commenters engaging with the blogs? Are commenters actively listening to and constructively responding to each other?

Examining blog comments in relation to these questions will give scholars greater insight into the nature of science communication happening in relationship to controversial science where dialogical conversations between publics and experts are needed. It will also have implications for science communication practitioners looking to engage publics in controversial science such as climate change through the use of science blogs. 
Overview of blogs and comments studied
Choice of blogs

The data analysed for this study were three sets of comments from three blog posts about the same three extreme climate/weather events on the two blogsites: https:/ /skepticalscience.com/ (SS) and http://joannenova.com.au/ (JN). These two climate change blogs were chosen because they are both:

(a)well-established — SS began posting in 2007 and JN in 2008; (b) have global reach - SS provides blogs in 20 different languages, and Sharman [2014] identified JN's blog as one of the three most central or influential sceptical blogs about climate change worldwide after comparing 171 blogs using social network analysis; (c) written by science communicators - SS was set up and is maintained by John Cook, a research assistant at the Center for Climate Change Communication at George Mason University while Joanne Nova is a pseudonym for Joanne Codling who has science communication qualifications and describes herself as "a self-employed science writer, graphic designer and illustrator, speaker and blogger"; and (d) aiming to use scientific information to support their claims and engage publics with climate science.

JN's blog seeks to refute the mainstream climate science views, being "dismayed that the good brand-name of science was being exploited". ${ }^{1}$ SS aims to: "gets skeptical about global warming skepticism. Do their arguments have any scientific basis? What does the peer reviewed scientific literature say?". ${ }^{2}$ An article written by John Cook on research he and others carried out into climate consensus [2014] says the purpose of the blog is to "refute climate misinformation with peer-reviewed science" [2014, p. 2]

SS has a tighter moderator's policy ${ }^{3}$ than JN and states that all comments must be on topic, that there is to be no politics, sloganeering, ad hominem attacks or cyber stalking. JN's 'Rules \& Legal' section, ${ }^{4}$ has a much freer policy, and says they welcome constructive comments and questions and that the site relies on commenters "to use logic and reason". The site also says: "If you are good-natured, funny or entertaining as well, you'll get away with breaking all the rules above". Comments are most likely to be deleted if they are "unnecessarily repetitive, rude, lazy or mindless, about administration/moderation, or too boring". The different moderation policies of both blogs create an interesting point of contrast, which this study takes into account.

\section{Choice of blogposts and comments}

I looked at three sets of blog comments (Table 1) made on three blogposts on each blogsite about the contentious issue of how climate/weather extremes link to climate change. The first of these was Typhoon Haiyan, which affected the Philippines in November 2013. The second was the heatwave that struck Australia in January 2014, and the last was the floods that affected the U.K. in February 2014. These three posts were made around the same time period on both blogs and were chosen due to the likely higher activity of commenters during such times of intense

\footnotetext{
${ }^{1}$ http://joannenova.com.au/about/.

${ }^{2}$ https://skepticalscience.com/.

${ }^{3}$ https://skepticalscience.com/comments_policy.shtml.

${ }^{4}$ http://joannenova.com.au/rules-legal/.
} 
media and public scrutiny of natural disasters and their likely connection to climate change. The time period of 2013-2014 was chosen due to their being global events of extreme weather in three different countries that generated a high level of discussion on social media, including blogs

Table 1. Blog comments investigated from Skeptical Science and Joanne Nova's blogs.

\begin{tabular}{|c|c|c|}
\hline $\begin{array}{l}\text { Climate/ } \\
\text { weather event }\end{array}$ & $\begin{array}{l}\text { Skeptical Science blog and number of } \\
\text { comments }\end{array}$ & $\begin{array}{l}\text { Joanne Nova blog and number of } \\
\text { comments }\end{array}$ \\
\hline $\begin{array}{l}\text { Typhoon Haiyan } \\
\text { affects the } \\
\text { Philippines, } \\
\text { November } 2013\end{array}$ & $\begin{array}{l}71 \text { comments across } 2 \text { blogposts; } \\
\text { Nov 16, 2013: } \\
\text { https://www.skepticalscience.com/ } \\
\text { super-typhoon-haiyan-michael- } \\
\text { mann.html } \\
\text { Nov 20, 2013: } \\
\text { https://www.skepticalscience.com/ } \\
\text { will-super-typhoon-haiyan-become- } \\
\text { norm.html }\end{array}$ & $\begin{array}{l}141 \text { comments; Nov 26, 2013: } \\
\text { http://joannenova.com.au/2013/11/ } \\
\text { sleepwalking-to-extinction-or-maybe- } \\
\text { communism/ }\end{array}$ \\
\hline $\begin{array}{l}\text { Heatwave affects } \\
\text { Australia, } \\
\text { January } 2014\end{array}$ & $\begin{array}{l}56 \text { comments; Jan 17, 2014: } \\
\text { https:/ / www.skepticalscience.com/ } \\
\text { australias-hottest-year-humans-caused- } \\
\text { it.html }\end{array}$ & $\begin{array}{l}260 \text { comments; Jan 16, 2014: } \\
\text { http:/ /joannenova.com.au/2014/01/ } \\
\text { forgotten-historic-hot-temperatures- } \\
\text { recorded-with-detail-and-care-in- } \\
\text { adelaide/ }\end{array}$ \\
\hline $\begin{array}{l}\text { Floods affect } \\
\text { United Kingdom, } \\
\text { February } 2014\end{array}$ & $\begin{array}{l}97 \text { comments; Feb 15, 2014: } \\
\text { https:/ / www.skepticalscience.com/ } \\
\text { 2014-SkS-Weekly-News- } \\
\text { Roundup_7.html }\end{array}$ & $\begin{array}{l}252 \text { comments; Feb 14, 2014: } \\
\text { http:/ /joannenova.com.au/2014/02/ } \\
\text { uk-met-office-predicts-15-chance-of- } \\
\text { heavy-rain-britian-gets-biblical-floods / }\end{array}$ \\
\hline
\end{tabular}

To investigate who was engaging with the blogs I used an open text field to code the names or pseudonyms of those commenting on each of the blog posts. When coding who was commenting I also noted where the language appeared to be scientific or very technical as opposed to colloquial. This provided quantitative date about who was commenting.

To determine the apparent motivations for commenters engaging with the blogs, I used thematic content analysis [Cho and Lee, 2014] to deductively code the possible motivations of all the individual comments in the six blogposts. This applied the objectives identified in the literature as described by Metcalfe [2019], and in particular the objectives to disseminate, promote, interest, educate, influence, provide access, discuss, debate or consult, with the last four objectives being specifically dialogical in nature. One comment might indicate multiple objectives. An independent researcher used a code guide to analyse a random sample of 25 comments from each of the six blogposts ( $17 \%$ of all comments) to compare with my coding [Lombard, Snyder-Duch and Bracken, 2004, suggests a sample of 10 is sufficient to test intercoder reliability]. There was 80 per cent agreement with my coding, but in discussions with the independent researcher, we agreed that it was difficult to determine the main motivations related to some comments. For example, it was difficult to differentiate whether a commentator was disseminating information or seeking to educate others. We agreed, that my coding results focus on obvious trends, and examples of those trends rather than any quantification of the coding. 
To then find out how commenters were engaging with each other, I analysed the blog comments to identify statements that indicated particular modes of participation that commenters had with each other and the blog. I used the four overall modes of participation identified by Kouper [2010] to code the data to determine whether blog comments were:

(1) Contributing to the topic - e.g. reporting from an external report or source; making an argument that adds to the topic, explaining more about the topic or asking questions of clarification

(2) Deviating from the topic - e.g. digressing, insulting, self-promotion

(3) Expressing attitudes or emotions - e.g. approval, disapproval, regret, personal experiences, anger

(4) Attempting to influence others' actions through advice, recommendations, requests and proposals.

Those commenters who are 'contributing' are more likely to be engaged in response to a dialogue with others, although they may also be engaged in one-way communication such as transmitting information, new ideas and data. Those who are 'deviating', 'expressing attitudes' or 'attempting to influence others' are likely to be also engaged in one-way communication rather than a dialogue. I analysed all comments, and each comment could have more than one mode of participation. An independent researcher tested my coding by using a code guide to analyse a random sample of 25 comments for each blogpost and found 90 per cent overall agreement with the original coding.

\section{Discourse analysis to investigate the quality of engagement}

This study investigated the quality of engagement commenters were having with each other through their discourse. Discourse analysis emphasises the contextual and rhetorical nature of the language used as people interact, and hence gives insights into how people engage with each other. This study's analysis builds on the concept of discourses being dialogically expansive or contractive [White, 2003]. Dialogically expansive conversations happen when commenters entertain other positions compared to what is being referenced (e.g. If we are seeing a rise in more extreme events, perhaps...) or where they attribute a viewpoint to one external voice among many (e.g. Dr. X claims...). This type of engagement is more likely to happen when the engagement is more two-way than one-way, and where participants dialogically actively listen and respond to each other.

Dialogically contractive discourses involve people engaging in one-way communication. Such discourses tend to close down conversations through statements that proclaim certainty for a point of view through pronouncements (e.g. I would contend that climate change is...), concurrence (e.g. Of course, there is no evidence...), or endorsement (e.g. Professor Y shows that...). Such dialogically contractive statements display the commenters "personal investment 
in the viewpoint being advanced and accordingly increases the interpersonal cost for any who would advance some dialogic alternative" [Kouper, 2010, p. 271]. Other dialogically contractive statements disclaim by denying (e.g. The new policy will not solve the problem) or countering (e.g. We already have the data available about...). Another form of dialogic contraction is justifying a specific viewpoint or position to win over or influence others (e.g. This interpretation of data is based on subjective analysis and therefore should be absolutely rejected...). Dialogically contractive discourse means that those engaged are less likely to be listening to each other or engaged in a more deliberative conversation.

All comments were coded, and each comment could indicate multiple types of engagement (as shown in Extract 1). An independent researcher conducted an intercoder reliability check by analysing a random selection of $17 \%$ of the comments using a code guide. There was 90 per cent overall agreement with my coding.

Across all three blog comments, SS had 55 different commenters making a total of 224 comments. JN had 179 commenters making 653 total comments. Of these commenters, SS had three who commented across all three blogs, making 29 per cent of all comments. JN had 20 commenters, also commenting on each of the three blogs, making 30 per cent of the comments. For both SS and JN's blogs, another third of comments were made by, respectively, 11 and 24 commenters, who commented on two of the three blogs. It is clear that over half of the comments (about $60 \%$ ) on both blogs were made by a core group of active commenters who made up about one quarter of the total number of commenters for each blog. Other commenters dropped into the blogsite conversations on occasion.

For both blogs, commenters with male names dominated compared to the few who had female names (see Table 2). It is possible that females may be disguising their participation through the use of male names [Armstrong and McAdams, 2009], and as such I can only comment on the dominance of assumed male names for commenters. SS had more pseudonyms compared to those clearly identified as male and JN had a majority of commenters who had assumed male names. In their survey of science blog readers, Jarreau and Porter [2018] also found that the majority (55\%) reported being male, which compared to 37 per cent identifying as female (the rest did not answer or identify as one of these sexes).

Table 2. The apparent gender of the blog commenters as a \% of all bloggers.

\begin{tabular}{|l|c|c|}
\hline Gender & Skeptical Science \% & Joanne Nova \% \\
\hline Male & 44 & 61 \\
Female & 2 & 4 \\
Pseudonym & 54 & 35 \\
\hline
\end{tabular}

More of the commenters from SS used formal, technical language compared to JN commenters who were more likely to engage in short quotes using colloquial language. In fact, a significant proportion of SS's commenters' contributions were 
so technical that even a reasonably well-educated person working in the climate change arena might have difficulty understanding the content. The scientific and technical nature of many of the comments is illustrated in an extract from a comment made by 'Tom Curtis', participating in the SS's blog on the U.K. floods. This level of detail is not unusual for SS commenters.

\begin{abstract}
Just addressing the evidence before the IPCC, we have OAGCCM models with equilibrium climate sensitivities ranging from 2 to $4.6 \mathrm{C} / \mathrm{x} 2 \mathrm{CO} 2 \ldots$

Empirically, from the instrumental record, we have values from 0.8 (Lindzen and Choi) to $5 \mathrm{C} / \times 2 \mathrm{CO} 2$, with 8 out of 20 being below $2 \mathrm{C} / \times 2 \mathrm{CO} 2$, and 5 being $3 \mathrm{C} / \mathrm{x} 2 \mathrm{CO} 2$ or above. Empirically, from climatological constraints we have three results, all lying between 3 and $4 \mathrm{C} / \mathrm{x} 2 \mathrm{CO} 2$.
\end{abstract}

It is possible that many of those participating in the blog as commenters are scientists or have a technical background, which may not be surprising given the aim of the blog is to convey the science of climate change. Jarreau and Porter [2018] likewise found in their survey that the vast majority of readers of scientific blogs were either pursuing or engaged in a science-related career.

\title{
Conversations between like-minded people
}

When looking at the apparent motivation of bloggers, about half of the comments for both SS and JN blogposts involved commenters conversing with each other in a discussion about a topic that interested them. These topics were often not related to the topic of the blogposts. For both blog sites, the conversations appeared to be between like-minded people who generally agreed with the stance taken by the others commenting on the blog. This focus on agreement rather than exploring or discussing any differences appears to indicate a lack of in-depth discussion within both blogs.

Around one third of the comments made on SS's blog posts appeared to be motivated by a desire to 'disseminate' information or to 'educate' people further about the science. For example, a comment by Michael Sweet in SS on the U.K. flooding blog indicates a desire to either disseminate or educate, or both:

Many here follow the Arctic Sea Ice. For those who don't, this sea ice map from Feb 20 shows astonishing melting near the North Pole. The North Pole is not imaged since the satellites do not fly directly over it, but it is clear that there are open areas of ocean at the North Pole in the middle of winter!

JN commenters appear to be much less likely to be motivated by dissemination or education objectives. JN commenters often made comments designed to interest or entertain other commenters in what they were saying. For example, regular JN commenter, Rereke Whakaaro, enters the Haiyan blog discussions to make a joke: "I was once told a joke by a Russian: 'Why do the KGB go around in threes? Well, one can read, and one can write, and the other is there to watch the intellectuals". This likely reflects the emphasis on entertainment in JN blog's Rules \& Legal ${ }^{5}$ section.

\footnotetext{
${ }^{5}$ http://joannenova.com.au/rules-legal/.
} 
In a few rare instances, someone who disagreed with the common stance of the majority of commenters for each blog entered the conversation. When they did so, their comments are usually fiercely debated by the dominant commenters. For example, climate change denier Russ R. makes 25 comments on SS's U.K. floods blogpost in a discussion where 20 other commenters made 72 remarks refuting what he said. More than half of the remarks (61\%) arguing against Russ R.'s comments were made by just four regular SS commenters. JN's commenters likewise refuted the comments of anyone who entered their conversation with a different view. For example, when Blackadderthe4th enters early into the JN commentary on the Haiyan blog ( $7^{\text {th }}$ commentator) he / she is attacked by $18 \mathrm{JN}$ commenters over the course of making five more comments, and then does not enter the commentary again. One of the commenters attacking Blackadderthe4th is the moderator, Jo Nova, who makes three comments, all personally derisive. For example, "BA. your blindness to the facts is truly cult-like. Thank you so much for fearlessly coming here as a case study on display". The behaviour of the moderator typifies the personal attacks on dissenters entering the JN blog commentary.

In each blog, there was only one example of more sophisticated engagement between commenters where they appeared to be motivated to actively deliberate about an issue. For example, climate change denier, Bruiser, makes ten comments on SS's Australian Heatwave blogpost, some of which cause Tom Curtis to rethink some of his analysis, although not his overall argument:

Bruiser will not be convinced, and nor should he be convinced, by this that he is wrong in attributing most of the increased temperature to the high solar exposure. The error margins are too large. Neither should he be convinced from this that he is correct, for the same reason. I have tried to be conservative in my calculation, and to the extent that I have succeeded, that means it is more likely that the errors will have favoured his case rather than undermined it, and therefore, that an error free calculation would show his case to be wanting. Therefore I do not believe we can use direct calculation of the transient forcing to further the discussion (contrary to what I attempted). This does not mean Bruiser should not be persuaded by the first part of my discussion.

A pro climate-change science commenter entering JN's Australian heatwave discussion, Philip Shehan, similarly has an ongoing dialogue with another commentator, Sheri B, about scientific publications. She ends that conversation by showing appreciation for his contributions:

I will read through the papers. Fascinating work. You kind of answered my first question. It seems some papers lay aside and show up much later! Still, there's a lot of good research out there that is never published, I would think.

Throughout their conversation, Philip and Sheri deliberate about the role and use of scientific publications. However, other commenters on JN's blog are rude to Philip and he stops contributing after Vic A Gallus posts: "What a $\mathrm{t} \# \mathrm{~d}$ ! It should have been obvious in my comments that I have published and reviewed papers. As I have a dig at an editor, it was best not to be specific, you idiot". This is an example of the incivility that can be created during such blog discussions, and which can further reduce the potential for more deliberative dialogue [Collins and Nerlich, 2015]. 
It appears that many commenters, especially from SS, engaged in the blogs to 'contribute' with new information, ideas or data (see Table 3). The other common mode of participation, especially for JN commenters, was to express some sort of attitude or emotion, as seen in Table 3.

Table 3. Modes of participation in blogs by commenters as a \% of total comments for each blogpost (Note. each comment may have more than one mode of participation).

\begin{tabular}{|l|r|r|r|r|r|r|}
\hline & \multicolumn{2}{|c|}{ Haiyan } & \multicolumn{2}{c|}{$\begin{array}{c}\text { Australian } \\
\text { heatwave }\end{array}$} & \multicolumn{2}{c|}{ U.K. Floods } \\
\hline Blog & SS & JN & \multicolumn{1}{|c|}{ SS } & JN & SS & JN \\
\hline Contribute & 61 & 24 & 93 & 52 & 74 & 42 \\
Deviate & 18 & 42 & 0 & 15 & 4 & 24 \\
Emote (show attitudes) & 25 & 70 & 13 & 51 & 59 & 53 \\
Influence & 21 & 7 & 0 & 0 & 3 & 0 \\
\hline
\end{tabular}

The attitudes or emotions expressed by JN commenters, which likely reflect the freer moderation policies of that blog, were generally directed at:

- An organisation (e.g. Australian Bureau of Meteorology / U.K. Meteorology Office);

- An individual (e.g. Julia Slingo from the U.K. Meteorology Office - "Dame Julia Slingo? The name says it all. HAHAHAHAHA!");

- 'Warmists' or 'Alarmists' who were perceived to be acting through a desire for personal gain;

- Experts;

- People who came into the debate who disagreed with the stance of the commenters; and

- Political policies, agendas or ideologies, especially those perceived to be socialist, communist or 'green'.

In line with the SS's tighter moderation policy, commenters were less likely to show their attitudes or emotions during a discussion. However, when someone with an opposing view entered the discussion, emotions still emerged. For example, when Russ R. entered SS's discussion about the U.K. floods, Tom Curtis, who generally tried to focus on the science, expressed his offense at Russ R.'s comments and demands an apology:

Russ R@82, I find it seriously offensive that mister 'only studies which find low climate sensitivity are valid' should accuse me of cherry picking... If you are going to accuse me of cherry picking for pointing to instances that falsify your claims, this discussion is over. If you want it to continue, I expect an apology.

JN's commenters were much more likely than SS's commenters to deviate from the topic, which also likely reflects their freer moderation policy. JN's commenters 
often deviated to topics that reflected their political leanings or sparked people's interest or sense of humour. For example, in response to the JN's blogpost about the U.K. floods, commenters deviated at length to discuss the names of rivers and which river in the world had the longest name.

Only a few commenters sought to influence people, and they were mostly SS commenters. For example, YubeDude comments on the SS's Haiyan typhoon post urging people to stick to the science:

\begin{abstract}
Any natural disaster is tragic where there is a loss of life or suffering. But adding that human element in an attempt to pull at heart strings is disingenuous when the speaker/negotiator knows that his government and the culture of corruption are standing in the way of real change... I say stick to the science and leave the tears to the TV dramas and bakla emotional meltdowns. (sic)
\end{abstract}

Commenters appear to be mostly using one-way communication to engage through the blogs, whether that be to contribute, deviate, express emotion or seek to influence. The results from Study 2 support those from Study 1, indicating a paucity of deliberative dialogue in either blog commentary about climate science.

\title{
Commenters engage in contractive discourse
}

The discourse in the comments on all six blog posts was mostly dialogically contractive in nature. More than half of all comments were proclamations of knowledge or information, indicating only one-way engagement between fellow commenters. SS commenters made almost as many comments that were disclaiming in nature, while a quarter of JN's comments were disclaiming. A smaller number of comments for both blogs justified a specific position. This is not surprising given the conversations appeared to happen mostly between like-minded people. The commenters on both blogs typically did not entertain alternative opinions to their own beliefs. Even when commenters debated a particular point, the nature of the discourse was largely contractive.

Commenters did not demonstrate that they were listening to each other and then responding, so no true dialogue was taking place. The dialogically contractive nature of the dialogue is illustrated in Extract 1 from JN's heatwave blog. This shows part of a discussion between an outsider (blackadderthe $4^{\text {th }}$ ) and regular JN commenters. Blackadderthe4th (BA) starts by proclaiming some facts through endorsing a BBC report. Heywood then responds to justify their viewpoint by implying that BA "falls for" the propaganda of the BBC. Heywood then goes on to disclaim BA's posting by pointing out that the whole country is not affected by the heatwave before proclaiming the issue as being about global warming. BA responds more expansively by endorsing a new source, Dr. Andrew Dessler. The moderator, Joanne Nova, then enters the conversation to disagree with and counter BA's comment. This sequence of comments is typical of most of the conversations in both blogs when someone with a different view enters the discussion. 
blackadderthe4th: As it is being reported in the U.K.! 'Australia heatwave prompts fire alerts' South-east Australia has been hit with extreme hot weather, with temperatures of over $40 \mathrm{C}(104 \mathrm{~F})$ in some areas, and several bushfire warnings in place... Last year was recently declared Australia's hottest on record, further raising questions about the impact of climate change, our correspondent adds... http:/ / www.bbc.co.uk/news/world-asia-257238

Heywood: Ahhh the good old BBC Climate Propaganda Unit, and BlackIdiotLevel4 falls for it. The BBC stooge falls for the same rhetoric. 'Last year was recently declared Australia's hottest on record'. Only in three states actually, not the whole country, but we mustn't let the truth get in the way of a good dose of scaremongering shall we. Luckily, the issue isn't Western Australian warming, or even Australian warming. It is GLOBAL warming...

blackadderthe4th, 'Ahhh the good old BBC', but not only the BBC! Dr. Andrew Dessler testimony: 'I am Andrew Dessler, I am a professor of atmospheric science... first the climate is warming... overall increase... the most recent warming is most likely due to the emissions of $\mathrm{co} 2$ and other GHG by human activity...

Jo [moderator comment]: BA I always admire how Dessler can frame a line that makes it look like the models "worked" in two specific small instances, while ignoring the failure in global trends, upper troposphere, the Antarctic, rainfall patters, and cloud cover. (sic)

Discussion and conclusions
In this study, I set out to examine the comments on two climate change blogs to determine how the conversations generated by these comments reflect the potential of blogs for two-way deliberative dialogue. The analysis of comments indicated that most commenters engaging with both blogs wanted to disseminate information and knowledge or express an attitude, which is more reminiscent of one-way communication. Discourse analysis also showed that most comments were contractive in nature with commenters proclaiming or disclaiming and not listening to the views of others.

The blogs examined appeared to create and maintain their own publics as a small number of dominant commenters sought and reinforced information congruent with their own views. This is a similar finding to an analysis by Collins and Nerlich [2015] of commenters to online Guardian articles on climate change. With each blog having a core group of commenters tending to dominate the dialogue, there is even less likelihood of significant deliberation amongst commenters. This is not surprising given science bloggers often aim to create publics with similar political and ideological points of view [Luzón, 2013].

The contractive nature of discussions reinforced the notion that these blogs were creating their own 'insular' publics, separate to more general publics. These findings reflect research into political blogs, which found that bloggers on those sites "focus on selectively spinning the issues at hand for their largely partisan audiences" [Meraz, 2011, p. 110]. Soon and Kluver [2014, p. 501] review the literature on political blogging and conclude that: "bloggers connect with others whom they perceive share similar ideologies". This results in separate and polarised blog sites with differing publics [Hewitt, 2005; Sunstein, 2007]. Researchers studying the Twitter conversations that followed the report from the 
2013 Intergovernmental Panel on Climate Change's Working Group found a similar result [Pearce, Holmberg et al., 2014, p. 9]: "people are more likely to make conversational connections with those who broadly share their views on climate change". Likewise, in their survey of science blog users, Jarreau and Porter [2018, p. 160] found that one of their significant motivations to engage was "to interact with a community of like-minded users". The relatively homogenous and separate groups that result from such discourses are likely to inhibit deliberative online dialogue about the science, and this is what my research into these two antithetical climate change blogs also found.

Commenters for both blogs did not engage deliberatively with those of opposing views. They were unwilling to explore alternatives or new ways of thinking about climate science knowledge. Rather, commenters in any debates on both blogs sought to advance their own rhetorical and ideological objectives. When an outsider joined the conversation, there was a tendency for commenters to focus on who was making the argument and how rather than the substance of the issue being debated. Wang's [2010] research into political blogs similarly found that commenters involved in campaign blogging focused on attacking opponents rather than developing political policies around issues. My in-depth analysis of the blogposts empirically supports and further develops Trench's [2012] review of scientists' blogs, which also noted a focus on the commenter rather than the substance of their discussion.

The style and nature of interaction between commenters was remarkably similar between the two blogs, and many of the differences between the discussions may be partly due to differing moderation rules. Skeptical Science's deliberate exclusion of political, social and economic issues from the discussion of climate change science reduced discussions about attitudes, policies and people's role in the science, which reduces the potential for more deliberative engagement among commenters. However, the strong partisan flavour of JN's blog and her freer moderation policy means the conversations often degenerated into attacking people and institutions rather than being reasoned discussions about the science. But it should be noted that the differing publics for each blog may also influence the nature of engagement. It would be interesting to compare two blogs with similar publics, but different moderation policies.

Both blogs failed to meet the five perceived benefits for dialogical engagement in science described at the beginning of this paper. Different views were not heard or valued by commenters on each blog. The voices of a mix of publics did not appear to be heard in each blogsite, as each developed their own insular publics. Those engaging in each blogsite narrowed their discussion rather than broadening their perspectives. Both blogs did offer perspectives outside of mainstream mass media, but there was little critical deliberation by commenters on these perspectives. In some cases, especially for the SS blogsite, scientists and science communicators did seek to explain the scientific contexts behind the news, however this was done in a dialogically contractive way rather than through deliberative dialogue.

\section{Limitations and further research}

The major limitation of this study is its focus on just two climate change blogs among many. There is also limited information on the differing publics 
commenting on these blogs with regard to their backgrounds and explicit motivations for being engaged. However, this study does provide some interesting reflections on the potential of blogs to create more deliberative dialogue with publics about controversial issues. By analysing the comments of those posting responses to controversial science blogs, we understand more about the limitations of such tools. Such research into blog comments has been done extensively for political blogs, but not for science blogs. It would be good to expand this research, for example by using tools other than textual analysis to explore the demographics and motivations of those engaging in such blogs.

Future research could look at the potential of blogs for engaging publics in other controversial science topics or in non-controversial science. When reviewing science blogs, Trench [2012] noted:
the case of climate science is in many respects special: Political and ideological factors are prominently in play, including through the involvement in the public debates of 'amateurs' who may have technical competence to follow the arguments but whose main motivation for becoming involved is to fight a cause.

If this is the case, then research may find that blogs on different controversial issues are more likely to attract more deliberative dialogue in their blog conversations.

This analysis of the comments on two antithetical climate change blogs indicates a narrowing of scientific debate to one dominated by a few major commenters who have little patience with others who disagree with their point of view; commenters are chanting to their own choir. This means that, at least for these two blogs, there is little deliberation of climate science and its role in society. Consequently, it is likely that such blogs are unlikely to engage publics more deliberately in a dialogue about publicly controversial science. Rather, the dialogue that occurs in these blogs offers spaces for like-minded people to share information on controversial science topics through one-way communication.

Acknowledgments I would like to thank Professor Brigitte Nerlich, Professor Warren Pearce, Professor Joan Leach, Dr. Sujatha Raman and Dr. Michelle Riedlinger for reviewing various drafts of this paper. I am especially grateful to Professor Nerlich who independently conducted the inter-coder reliability tests on my coding of the data.

\section{References}

Armstrong, C. L. and McAdams, M. J. (2009). ‘Blogs of information: how gender cues and individual motivations influence perceptions of credibility'. Journal of Computer-Mediated Communication 14 (3), pp. 435-456. https://doi.org/10.1111/j.1083-6101.2009.01448.x.

Bell, A. R. (2012). 'Has blogging changed science writing?' JCOM 11 (01), C02. https://doi.org/10.22323/2.11010302.

Bubela, T., Nisbet, M. C., Borchelt, R., Brunger, F., Critchley, C., Einsiedel, E., Geller, G., Gupta, A., Hampel, J., Hyde-Lay, R., Jandciu, E. W., Jones, S. A., Kolopack, P., Lane, S., Lougheed, T., Nerlich, B., Ogbogu, U., O'Riordan, K., Ouellette, C., Spear, M., Strauss, S., Thavaratnam, T., Willemse, L. and Caulfield, T. (2009). 'Science communication reconsidered'. Nature Biotechnology 27 (6), pp. 514-518. https://doi.org/10.1038/nbt0609-514. 
Cahill, J. and Ward, I. (2007). 'Old and new media: blogs in the third age of political communication'. Australian Journal of Communication 34 (3), pp. 1-21.

Carvalho, A. (2010). 'Media(ted) discourses and climate change: a focus on political subjectivity and (dis)engagement'. Wiley Interdisciplinary Reviews: Climate Change 1 (2), pp. 172-179. https://doi .org/10.1002/wcc. 13.

Cho, J. Y. and Lee, E.-H. (2014). 'Reducing confusion about grounded theory and qualitative content analysis: similarities and differences'. The Qualitative Report 19 (32), pp. 1-20. URL: https: //nsuworks . nova.edu/tqr/vol19/iss32/2/.

Collins, L. and Nerlich, B. (2015). 'Examining User Comments for Deliberative Democracy: A Corpus-driven Analysis of the Climate Change Debate Online'. Environmental Communication 9 (2), pp. 189-207. https://doi.org/10.1080/17524032.2014.981560.

Colson, V. (2011). 'Science blogs as competing channels for the dissemination of science news'. Journalism 12 (7), pp. 889-902. https://doi.org/10.1177/1464884911412834.

Cook, J. (6th May 2014). 'Research on climate consensus provokes strong reactions'. The Winnower. https://doi.org/10.15200/winn.140076.68926.

Elgesem, D., Steskal, L. and Diakopoulos, N. (2014). 'Structure and content of the discourse on climate change in the blogosphere: the big picture'. Environmental Communication 9 (2), pp. 169-188. https://doi.org/10.1080/17524032.2014.983536.

Graham, T. (2013). 'Talking back, but is anyone listening? Journalism and comment fields'. In: Rethinking journalism: trust and participation in a transformed news landscape. Ed. by C. Peters and M. J. Broersma. London, U.K.: Routledge, pp. 114-127. https://doi.org/10.13140/RG.2.1.4625.4240.

Grant, R. P. (23rd August 2016). 'Why scientists are losing the fight to communicate science to the public'. The Guardian.

URL: https://www. theguardian.com/science/occams-corner/2016/aug/23/s cientists-losing-science-communication-skeptic-cox.

Hewitt, H. (2005). BLOG: understanding the information reformation that's changing your world. Nashville, TN, U.S.A.: Thomas Nelson.

Horst, M. and Michael, M. (2011). 'On the shoulders of idiots: re-thinking science communication as 'event". Science as Culture 20 (3), pp. 283-306. https://doi.org/10.1080/09505431.2010.524199.

Huber, B., Wetzstein, I. and Aichberger, I. (2019). 'Societal problem solver or deficient discipline? The debate about social science in the online public sphere'. JCOM 18 (02), A04. https://doi.org/10.22323/2.18020204.

Irwin, A. and Wynne, B. (1996). 'Introduction'. In: Misunderstanding science? The public reconstruction of science and technology. Ed. by A. Irwin and B. Wynne. Cambridge, U.K.: Cambridge University Press, pp. 1-18. https://doi.org/10.1017/cbo9780511563737.

Jackson, R., Barbagallo, F. and Haste, H. (2005). 'Strengths of public dialogue on science-related issues'. Critical Review of International Social and Political Philosophy 8 (3), pp. 349-358. https://doi .org/10.1080/13698230500187227.

Jarreau, P. B. and Porter, L. (2018). 'Science in the social media age: profiles of science blog readers'. Journalism \& Mass Communication Quarterly 95 (1), pp. 142-168. https://doi.org/10.1177/1077699016685558.

Jenkins, H. (2006). Convergence culture: where old and new media collide. New York, U.S.A.: New York University Press. 
Joly, P.-B. and Kaufmann, A. (2008). 'Lost in translation? The need for 'upstream engagement' with nanotechnology on trial'. Science as Culture 17 (3), pp. 225-247. https://doi .org/10.1080/09505430802280727.

Kahan, D. M., Peters, E., Wittlin, M., Slovic, P., Ouellette, L. L., Braman, D. and Mandel, G. (2012). 'The polarizing impact of science literacy and numeracy on perceived climate change risks'. Nature Climate Change 2, pp. 732-735. https://doi.org/10.1038/nclimate1547.

Kahle, K., Sharon, A. J. and Baram-Tsabari, A. (2016). 'Footprints of fascination: digital traces of public engagement with particle physics on CERN's social media platforms'. PLOS ONE 11 (5), e0156409. https://doi.org/10.1371/journal.pone.0156409.

Kouper, I. (2010). 'Science blogs and public engagement with science: practices, challenges, and opportunities'. JCOM 09 (01), A02.

URL: https://jcom.sissa.it/archive/09/01/Jcom0901\%282010\%29A02.

Kurath, M. and Gisler, P. (2009). 'Informing, involving or engaging? Science communication, in the ages of atom-, bio- and nanotechnology'. Public Understanding of Science 18 (5), pp. 559-573. https://doi.org/10.1177/0963662509104723.

Lee, N. M., VanDyke, M. S. and Cummins, R. G. (2018). 'A missed opportunity?: NOAA's use of social media to communicate climate science'. Environmental Communication 12 (2), pp. 274-283. https://doi.org/10.1080/17524032.2016.1269825.

Lemonick, M. D. (2010). 'Climate heretic. Why can't we have a civil conversation about climate?' Scientific American 303 (5), pp. 78-83. https://doi.org/10.1038/scientificamerican1110-78.

Lombard, M., Snyder-Duch, J. and Bracken, C. C. (2004). Practical resources for assessing and reporting intercoder reliability in content analysis research. URL: http://matthewlombard.com/reliability/.

Lörcher, I. and Taddicken, M. (2017). 'Discussing climate change online. Topics and perceptions in online climate change communication in different online public arenas'. JCOM 16 (02), A03. https://doi .org/10.22323/2.16020203.

Luzón, M. J. (2013). 'Public Communication of Science in Blogs: Recontextualizing Scientific Discourse for a Diversified Audience'. Written Communication 30 (4), pp. 428-457. https: //doi .org/10.1177/0741088313493610.

Meraz, S. (2011). 'The fight for 'how to think': traditional media, social networks and issue interpretation'. Journalism: Theory, Practice $\mathcal{E}$ Criticism 12 (1), pp. 107-127. https://doi.org/10.1177/1464884910385193.

Metcalfe, J. (2019). 'Comparing science communication theory with practice: an assessment and critique using Australian data'. Public Understanding of Science 28 (4), pp. 382-400. https://doi .org/10.1177/0963662518821022.

Miller, S., Fahy, D. and the ESConet Team (2009). 'Can Science Communication Workshops Train Scientists for Reflexive Public Engagement?' Science Communication 31 (1), pp. 116-126. https://doi.org/10.1177/1075547009339048.

Mohr, A., Raman, S. and Gibbs, B. (2013). Which publics? When? Exploring the policy potential of involving different publics in dialogue around science and technology. URL: http://eprints.nottingham.ac.uk/id/eprint/2896.

Nisbet, M. C. and Scheufele, D. A. (2004). 'Political talk as a catalyst for online citizenship'. Journalism \& Mass Communication Quarterly 81 (4), pp. 877-896. https://doi.org/10.1177/107769900408100410. 
Pearce, W., Brown, B., Nerlich, B. and Koteyko, N. (2015). 'Communicating climate change: conduits, content and consensus'. Wiley Interdisciplinary Reviews: Climate Change 6 (6), pp. 613-626. https://doi.org/10.1002/wcc. 366.

Pearce, W., Holmberg, K., Hellsten, I. and Nerlich, B. (2014). 'Climate Change on Twitter: Topics, Communities and Conversations about the 2013 IPCC Working Group 1 Report'. PLoS ONE 9 (4), e94785. https://doi.org/10.1371/journal.pone.0094785.

Peters, H. P., Dunwoody, S., Allgaier, J., Lo, Y.-Y. and Brossard, D. (2014). 'Public communication of science 2.0: Is the communication of science via the "new media" online a genuine transformation or old wine in new bottles?' EMBO reports 15 (7), pp. 749-753. https: //doi .org/10.15252/embr . 201438979. PMID: 24920610.

Readfearn, G. (2010). 'Blogging on climate change - job for the brave'. Ecos 154 (April), p. 31. URL: http://www . ecosmagazine. com/?paper=EC154p31.

Riesch, H. and Mendel, J. (2013). 'Science blogging: networks, boundaries and limitations'. Science as Culture 23 (1), pp. 51-72. https://doi.org/10.1080/09505431.2013.801420.

Ritson, S. (2016). "Crackpots' and 'active researchers': the controversy over links between arXiv and the scientific blogosphere'. Social Studies of Science 46 (4), pp.607-628. https://doi.org/10.1177/0306312716647508.

Roberts, D. (14th August 2013). 'The futility of "just the facts" climate science'. Grist. URL: http://grist.org/climate-energy/the-futility-of-just-the-f acts-climate-science/.

Schäfer, M. S. (2012). 'Online communication on climate change and climate politics: a literature review'. Wiley Interdisciplinary Reviews: Climate Change 3 (6), pp. 527-543. https://doi.org/10.1002/wcc.191.

Schmidt, G. (2008). 'To blog or not to blog?' Nature Geoscience 1 (4), pp. 208-208. https://doi.org/10.1038/ngeo170.

Sharman, A. (2014). 'Mapping the climate sceptical blogosphere'. Global Environmental Change 26, pp. 159-170. https://doi.org/10.1016/j.gloenvcha.2014.03.003.

Soon, C. and Kluver, R. (2014). 'Uniting political bloggers in diversity: collective identity and web activism'. Journal of Computer-Mediated Communication 19 (3), pp. 500-515. https://doi.org/10.1111/jcc4.12079.

Sunstein, C. R. (2007). Republic.com 2.0. Princeton, NJ, U.S.A.: Princeton University Press.

Swain, K. A. (2012). 'Mass media roles in climate change mitigation'. In: Handbook of climate change mitigation. Ed. by W. Y. Chen, J. Seiner, T. Suzuki and M. Lackner. New York, NY, U.S.A.: Springer, pp. 161-195. https://doi.org/10.1007/978-1-4419-7991-9_6.

Trench, B. (2008). 'Towards an analytical framework of science communication models'. In: Communicating science in social contexts. Dordrecht, The Netherlands: Springer, pp. 119-135. https://doi.org/10.1007/978-1-4020-8598-7_7.

- (2012). 'Scientists' Blogs: Glimpses Behind the Scenes'. In: The Sciences' Media Connection - Public Communication and its Repercussions. Ed. by S. Rödder, M. Franzen and P. Weingart. Vol. 28. Sociology of the Sciences Yearbook. Dordrecht, The Netherlands: Springer, pp. 273-289. https://doi.org/10.1007/978-94-007-2085-5_14. 
Wang, T.-L. (2010). 'A comparative study of campaign blogs and web sites: the case of Taiwan's 2008 general election'. Online Information Review 34 (2), pp. 229-249. https://doi.org/10.1108/14684521011036963.

White, P. R. R. (2003). 'Beyond modality and hedging: a dialogic view of the language of intersubjective stance'. Text - Interdisciplinary Journal for the Study of Discourse 23 (2), pp. 259-284. https://doi .org/10.1515/text.2003.011.

Wilcox, C. (2012). 'Guest Editorial. It's Time To e-Volve: Taking Responsibility for Science Communication in a Digital Age'. The Biological Bulletin 222 (2), pp. 85-87. https://doi.org/10.1086/BBLv222n2p85.

Wilkins, J. S. (2008). 'The roles, reasons and restrictions of science blogs'. Trends in Ecology E Evolution 23 (8), pp. 411-413. https://doi.org/10.1016/j.tree.2008.05.004.

Yuan, S., Oshita, T., AbiGhannam, N., Dudo, A., Besley, J. C. and Koh, H. E. (2017). 'Two-way communication between scientists and the public: a view from science communication trainers in North America'. International Journal of Science Education, Part B 7 (4), pp. 341-355.

https://doi.org/10.1080/21548455.2017.1350789.

Author

\section{How to cite}

(C) The Author(s). This article is licensed under the terms of the Creative Commons Attribution - NonCommercial — NoDerivativeWorks 4.0 License.

ISSN 1824-2049. Published by SISSA Medialab. jcom.sissa.it
Jennifer Metcalfe is Founder of Econnect Communication, established in 1995 to help scientists communicate their research. As a science communicator for 30 years, she has worked as a journalist, practitioner, university lecturer and researcher. Jenni is a foundation member of the Australian Science Communicators and has been a member of the scientific committee of the International Public Communication of Science and Technology (PCST) Network since 1996. Jenni believes every person has a right to engage with science, so they can make more informed decisions about issues that affect their lives. E-mail: jenni@econnect.com.au.

Metcalfe, J. (2020). 'Chanting to the choir: the dialogical failure of antithetical climate change blogs'. JCOM 19 (02), A04. https:/ / doi.org/10.22323/2.19020204. 